\title{
Absenteeism Problems And Costs: Causes, Effects And Cures
}

\author{
Mehmet C. Kocakülâh, University of Southern Indiana, USA \\ Ann Galligan Kelley, Providence College, USA \\ Krystal M. Mitchell,Life Point Hospitals, Inc., USA \\ Margaret P. Ruggieri, Providence College, USA
}

\begin{abstract}
Employee absences are both costly and disruptive for business, and the trend has been increasing steadily over the years. Personal illness and family issues are cited as the primary reason for unplanned absences. Employers have been attempting to determine the validity of these illnesses and offer incentives and propose possible solutions to mitigate these absences, including those caused by family issues. Illness, family responsibilities, personal issues and stress all take a toll on the worker which in turn affects morale, absences and productivity in the workplace. Some sources including Statistics Canada cite that absenteeism approximates 15-20 percent of payroll (direct and indirect) costs. This is significant. Canada Newswire stated on May 23, 2008 that absenteeism translates into losses of over $\$ 16$ billion in salary expenses. The purpose of this paper is to identify the leading factors of absenteeism, possible "cures" that exist for these factors, and present results of companies that have implemented programs to combat the problem of absenteeism. It is important that businesses determine if they in fact have an absenteeism problem and thus consider utilizing some of the proposed solutions offered in this paper.
\end{abstract}

Keywords: Absenteeism, stress, Costs, Cures

\section{INTRODUCTION}

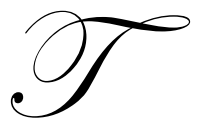

he Bureau of Labor Statistics estimates that nearly 2.8 million workdays are lost each year due to employee absences (Truman, 2003). One study estimated that if "illness-related absenteeism were a line item on a company's profit and loss statement, the cost would probably exceed $15 \%$ of the profits, and the accounting doesn't include lost productivity and missed deadlines, the costs for replacement staff and overtime pay for the replaced workers, and lowered morale costs" (HR Focus, 2003). Broken down, this amounts to an average annual cost of $\$ 789$ per employee in 2002 (Truman, 2003). This trend has only been increasing. Statistics Canada cites that the average full-time employee lost 10.2 days for personal reasons in 2007 (8.1days for own illness or disability plus 2.1 for personal or family demands) which has increased steadily from 7.4 days lost by each employee in 1997. [See Table 1]. On an April 2007 survey by Harris Interactive, a leading market research firm, $30 \%$ of the 1,077 full-time adult employees surveyed responded that they might call in sick to enjoy a day off during the summer vacation season. The $16^{\text {th }}$ annual CCH Unscheduled Absence Survey conducted in 2006 indicates that nearly 2 out of 3 absent employees were not sick. Only 35\% of unscheduled absences were for personal illness.

While most employers utilize disciplinary type actions to solve the absenteeism problem, others are using incentives to reduce absenteeism. Absenteeism has been defined as a root cause of losses in productivity and company performance (Neuborne, 2003). Given that the typical worker takes nine days off each year, it is not surprising that employers are weary of lost revenues (Whittle, 2004).

Long-term physical illnesses are more significant for manual employees, while recurring illnesses are more common among non-manual employees. Long-term absences have the greatest impact on business, resulting in over 40 percent of total working time lost (Haswell, 2003). While these statistics are staggering, what may reveal to be 
more surprising is that many American employers have no idea the extent of the problem. Since many employers are unaware of the significant cost of employee absenteeism, only about half have a system in place to track absenteeism within their company, while only 16 percent have the tools to reduce it once they have tracked it (Kaleta, 2003). The need to determine how much these absences cost companies is more prevalent than ever, with a fairly recent study stating that small businesses are losing as much as $\$ 60,000$ per year and the largest employer involved in the study losing $\$ 3.6$ million annually (Truman, 2003).

\section{CAUSES}

The U.S. service sector alone loses $2.3 \%$ of all scheduled labor hours to unplanned absences, but in some industries, the total cost of unplanned absences approaches $20 \%$ of payroll expense. The principal reasons for unscheduled absences (personal illness and family issues) are unlikely to abate anytime soon. (Easton \& Goodale 2005). In 2002 personal illness accounted for 33 percent of unscheduled absences. The remainder of missed days was due to family issues (24\%), personal needs (21\%), stress (12\%), and entitlement mentality (10\%) (Truman, 2003). While personal illness is certainly a given reason for not coming to work, companies are now attempting to determine whether the employee is actually sick when they call in. Certainly if an employee is physically ill and unable to perform his job, the employee should not be at work. It is not uncommon though for an employee to miss work due to minor aches and pains.

Family issues also play a crucial role in absenteeism. Balancing work and family life can be a struggle. Childcare is often a major issue. With the cost of childcare rising we will see more individuals that are unable to pay higher rates. Many workers already send their children to private residences or to a small day care to reduce costs. But, what happens when the person who owns and operates this day care falls sick? It is quite inconvenient for an employee to be on their way out the door with the child or children only to have the phone ring with a person on the other end of the line informing them that they are going to have to send their child to another place for the day and perhaps tomorrow because the caregiver is ill. Often, the employee then has to either be late for work after the problem is resolved or take the day off in order to care for their child.

Another commonality among family issues is the responsibility that adult children have to care for their elderly parents. A recent study by the National Alliance for Caregiving and AARP indicated that more than 44 million Americans provide some sort of care for a family member or friend 18 years or older. Many of these individuals are caring for elderly parents at home rather than sending them to a nursing care facility. When this happens, it adds additional responsibility and time constraints to the working individual in order that their parents' needs are met. These needs could include doctor/medical testing appointments, hospitalizations, et cetera, all of which take time to complete.

In addition, the ugly word divorce can play a huge role in time needed off from work. Divorces are common and often take a toll on the entire family. Sometimes the divorce proceedings can take years, which equates to multiple court appearances. Each court appearance will mean a half or whole day off from work. Furthermore, the rollover effect of a divorce can be emotional issues that may cause an individual to need additional time off from work.

\section{PERSONAL NEEDS}

As with any valuable tangible property, maintenance is critical to retaining and improving the worth of the item. The same holds true for the human body. It is critical that individuals seek periodic medical attention, including regularly scheduled "healthy" checkups. Doctor offices have gotten better about keeping longer hours in the past few years but could still use improvement. It is often difficult for individuals to work a full day and be able to schedule a needed doctor's appointment that does not interfere with their scheduled work day. This costs both the worker and the employer much needed time, which can never be recovered. 


\section{STRESS}

Although stress accounts for only 12 percent of absenteeism a year, the monetary costs that stress imposes on a company are significant. The Health and Safety Executive claims 6.5 million sick days are taken every year as a result of stress alone (Haswell, 2003). In the United States, job stress has been estimated to cost industry about $\$ 200$ billion annually, and in the UK stress has led to the loss of 10 percent of the GNP (Bradford). As many as one in five people suffer from high levels of work-related stress. According to Shepell-fgi Research Group, the annual cost of depression in Canada is estimated to be $\$ 33$ billion with depression accounting for higher employee absenteeism than back pain, cardiovascular disease, hypertension, diabetes and other mental conditions. The U.S. Census Bureau's 2005 American Community Survey estimated that on average Americans commute to and from work an average of 100 hours per year. Not only can this lead to stress related health problems but may also cause increased rates of tardiness and absenteeism as well as increased resentment towards their jobs. (Jackson, 2008). Depression and antidepressant prescriptions are major contributing factors to employer health care costs, which are rising by $15 \%$ a year. (Canada News Wire 2008) Furthermore, a 2006 Canadian review indicates that another major issue for employees with depression and anxiety disorders is 'presenteeism,' or lost productivity while at work.

The causes of stress, or the stressors, are numerous and can be found anywhere in the workplace. Stressors can include dangerous working conditions, long working hours, job security worries and job monotony (Bradford). This stress can lead to poor mental health, heart disease, back pain, and gastrointestinal disturbances. It can also lead to unaccommodating behaviors such as drinking too much alcohol and smoking. Stress can cause accidents. One investigation stated that of all factors related to the cause of accidents, only one emerged as a common denominator--a high level of stress at the time the accident occurred (Bradford). All of this culminates to lowering morale among employees and lowering productivity because of poor performance (Haswell, 2003). The end result can be job burnout where the worker has no energy left to put forth, is dissatisfied, pessimistic, and has very low resistance to illness (Bradford).

What does this cycle mean for the employer? Stress can lead to seeking alternate employees, which costs the employer money in the form of recruitment and training. What's more, stress can overburden co-workers with additional responsibilities while replacement personnel are hired. This can lead to a heavier workload for already distraught employees, which affects their health and eventually results in even more absenteeism (Haswell, 2003).

\section{EFFECT OF ABSENTEEISM ON COMPANIES}

Absenteeism is costly for companies. A major airline revealed that unscheduled absences were costing them nearly \$1 million per day (Kaleta, 2003). A human resources information provider showed that an average annual cost of absences to employers amounted to a record $\$ 789$ per employee in 2002 . This number rose despite a decrease in absenteeism rates from 2.2 percent to 2.1 percent (Truman, 2003). Furthermore, approximately 14.3 percent of every business' payroll comes from time off (Lombardo, 2003). Various sources including Statistics Canada indicate that absenteeism represents between $15 \%$ and $20 \%$ of all direct and indirect payroll expenses in Canada. "Divided over the entire working population, it adds up to nine workdays missed for every full-time employee, which translates into losses of over $\$ 16$ billion in salary expenses." (Canada NewsWire May 23, 2008) Therefore, absenteeism has a large effect either directly or indirectly on a company's bottom line. The costs associated with dealing with absenteeism are significant when everything involved is taken into account. One cannot look at just what it costs to replace the employee for a day. It is necessary to look at what it is going to cost to lighten the load and attempt to attack these ongoing ever-increasing problems in the workplace. One also has to look at the increase in corporate health benefit costs that will result if a hands-off policy is adopted and absenteeism is not taken seriously (Quinley, 2003).

\section{AN ANALYSIS OF ABSENTEEISM}

How do you know if a company has an absenteeism problem? The following discussion will address some issues to assist an employer in determining if a problem exists as well as possible causes and solutions. The initial cue is called the four earlies: early identification, early intervention, early treatment and early return to work (Felix, 98). The first place to begin is to understand the problem (Kaleta, 2003). A solution cannot be chosen until the 
extent of the problem is known. In order to understand the problem, absence related data needs to be collected in a form that is easily interpreted. Next, determine the root causes of absenteeism (Poirier, 2003). What is the reason for the absences? Is there a common factor that is driving absences up across the board? If so, what is the cause of that? Lastly, the company needs to set up a plan of intervention. One article concludes that implementing basic changes can produce dramatic results (Kaleta, 2003). The company can recognize gains in both efficiency and productivity almost immediately. By completing these few simple steps, a company can save themselves a large amount of money by keeping talented workers happy and satisfied and identifying problem employees.

\section{SOLUTIONS/CURES}

As previously discussed, there are many causes for absenteeism in the workplace. Consequently, there are many different methods that can be used to combat the problem and alleviate the causes. What determines which solution is best depends on how a company wants to direct their resources and energy. Another determinant is how significant a problem the company views absenteeism. Throughout the remainder of this section of the paper, we will discuss several possible solutions for companies.

\section{DISCIPLINARY PROCEEDINGS/ABSENCE MANAGEMENT PROGRAM}

First and foremost, companies have the power to move forward with disciplinary proceedings if absenteeism becomes a problem within their company. This is usually practiced at a per employee basis. Some companies question an employee after one absence just to determine why the employee was absent. In the UK, a recent news article reports that some "UK businesses are using lie detectors with a new generation of voice analysis systems to crack down on employees who pull sickies". (May 16, 2008 The Daily Mail). Some would view this as a scare tactic showing that there will be ramifications if continued absenteeism ensues. An alternative approach is an absence management program. This requires employees to complete forms and provide evidence from a doctor to qualify for sick days (Poirier, 2003). If the given reasons do not qualify for a sick day, then wages are either reduced or personal days are forfeited. When implemented correctly, this type of program can decrease absences by up to 30\% (Poirier, 2003).

\section{EMPLOYEE ASSISTANTSHIP PROGRAMS}

When tackling the absenteeism problem companies often need to focus their energies on non work-related issues. This can prove to boost both productivity and to curtail disability costs (Quinley, 2003). Employee assistance programs (EAPs) can be implemented to help workers deal with issues outside of work that employees bring to the workplace. Under most EAPs, employers give their employees the names and numbers of an outside service that can be called for help. The goal is to minimize the effect that issues such as parenting and marital issues have on the worker while on the job (Quinley, 2003). Said issues obviously will determine how efficiently and effectively workers do their job. In industrial environments, a study shows that EAPs can reduce confrontations, accidents, and workers' compensation cases that result from off the job stress, which leads to a reduction in unplanned days off (Quinley, 2003). Those who volunteered information about EAPs within their workplace gave positive feedback. Employees concluded that because their employer provides such a program it helps with their return to work and it makes them feel that their employers care about their well being, thus emphasizing their importance to the company. However, EAPs are expensive and it is difficult to monitor whether their usefulness is substantial. This is primarily due to privacy issues, but many employers feel that they help. The six traits of highly successful employee assistance programs include (Quinley, 2003):

\footnotetext{
* Short-term counseling for mental health, alcohol abuse, and substance abuse issues

* Ongoing public relations to encourage employee use of EAPs

* Employee workshops (including but not limited to smoking cessation, nutrition and diet counseling, exercise and stress management issues)

* Management consultations and supervisory training

* Resource and referral for life/work issues

* Legal and financial services
} 
Once a program is in place, it should be monitored. Constant reminders of a company's EAP program should be given to employees as a great way to maximize its benefits. Suggestions should be made to employees of situations where they might benefit from using the EAP system. Employees love to hear when something is offered as a benefit for them. Publicize the EAP system as a wonderful benefit created for the employee. Furthermore, allowing employees to vent their feelings about whatever is causing their anger, depression, sickness, et cetera, is going to improve productivity and attendance, thus benefiting the employer. With this EAP concept, a company can save money from reduced absences and likely increase revenues from increased productivity.

\section{CREATION OF POSITIVE COMPANY CULTURE}

Many employers believe absenteeism can be reduced before it begins by making the workplace a positive and welcoming environment. A positive company culture helps to promote job satisfaction and job satisfaction is one of the most important factors in reducing absenteeism. Having clear expectations with regard to employee and company expectations and ensuring that there is a true match is important in establishing job satisfaction (Truman, 2003). Some studies have indicated that a lack of management knowledge of the employees' real perceptions and feelings about the organization have negatively impacted corporate culture. An effective tool is to distribute anonymous employee surveys and communicate seriously from the top down. Anonymous web-based employee surveys are becoming more popular, and offering incentives such as cash or gift certificates can be used to increase the response rate. At Avery Dennison, an employee board is established with its own budget and is responsible for putting together company parties that can be enjoyed both by the employee and their family (Truman, 2003). Another key to fostering a positive company culture and employee happiness is a quarterly meeting that allows the employees to ask candid and up-front questions to executives about company goals and policies. Other companies offer tuition reimbursement, employee health club memberships, and allow participation in new employee reviews (Truman, 2003). Wellness programs also have been shown to help employee morale. It is all about having a good place to work, which in turn, causes employees to want to be there. Their jobs are not a depressing, draining a portion of their lives. Allowing employees to bring food to work at regularly scheduled intervals and offering continental breakfasts are added perks that some companies vow is worthwhile (Truman, 2003). The companies that take this approach toward diminishing absenteeism in their company emphasize that their company culture is what makes the difference. GlaxoSmithKline (GSK) pharmaceutical company has more than 100,000 employees in 166 countries. Their employees felt that their job demands were "excessive" according to a staff survey and only 22 percent felt engaged. "Almost $40 \%$ of senior staff felt engaged but compromised in terms of energy and resilience". (Personnel Today June 3, 2008) GSK developed a set of management tools to foster personal resilience in employees and to deal with work related stress. Their corporate culture was redesigned to now minimize pressure and required a health risk appraisal as well as an early intervention approach to attendance management. Dr Adrian Chojnacki, vice-president of employee health management for GSK states that it is important to "focus on ...behaviours that will create a more supportive work environment". Since the program began in 2003, work-related mental ill health cases at GSK have decreased by $60 \%$, and all mental ill health absence has fallen by $20 \%$.

\section{CHILDCARE AND FLEXIBLE SCHEDULING}

Company childcare support is an invaluable benefit for employees with young children. In just one year, a backup child-care program saved a company more than 2,500 lost days (Brown, 2003). The center was created especially for employees who have nowhere else to turn when their babysitter calls in sick. When this company was exploring the possibility of a corporate affiliated day care service, they forecasted that around 395 employees would register for the service and that an estimated 1,400 absences would be avoided. Instead, an amazing 800 employees had registered and an estimated 2,528 missed days were saved (Brown, 2003). Around 68\% of the parents who registered and brought their children in to the center for care said that they would have missed work if it were not for the corporate sponsored day care center. The employee satisfaction from this added benefit is really a relevant point. When employees are happy they will continue to diligently work toward not missing days from employment. This solution offers an alternative where the benefits far outweigh the costs. Another possible solution is offering arrangements for employees to work from home ("telecommute"). This can "make significant improvements in their productivity, job satisfaction, personal budget, and overall quality of life. Employers benefit from employees working from home as efficiency and productivity increase, while overhead and occupancy costs decrease." (Jackson, 2008). 


\section{INCENTIVES}

Employee incentive programs to help reduce absenteeism have been used in the business world for quite some time. This type of program is affectionately termed the "carrot approach" rather than the "stick approach". Incentives can be offered in several different ways. One way that companies introduce their incentive based programs is to pay their employees for every sick and personal day that employees do not take. At the end of each year, the employees receive a check for their unused days. Employers who use this approach confirm that their operations run smoothly and efficiently. (Neuborne, 2003). As for the employees' reward, nothing talks better than cold, hard cash.

For some companies though, this approach is a little too cash invested for them. Instead, several businesses studied established an incentive program for perfect attendance. For example, one company has a drawing every three months for $\$ 500$, and entrance to the drawing requires perfect attendance. A large airline company offers an opportunity for employees to win a new Eddie Bauer-edition Ford Explorer. The program allows each employee with a six-month perfect attendance to enter to win (Neuborne, 2003). So far more than 100 vehicles have been awarded, and over 16,000 workers were eligible to win in the last drawing. Additionally, one company based its incentive program on the actual number of hours worked. This program awards a gift certificate at a local shopping facility if the bimonthly benchmark number of hours is met. (HR Focus, 2003). A separate program is used quarterly by the same company for both attendance and safety requirements.

Other companies merely offer time off for perfect attendance each quarter and a day's pay at the end of a year (Truman, 2003). Companies also offer a company party, a company picnic, or a corporate gift for perfect attendance (Poirier, 2003). While some researchers caution that rewarding employees for something that they should already be doing results in an expectancy for things to come, others conscientiously endeavor to keep their employees happy and working. Whatever solution is chosen should be adopted and continually monitored to check successfulness. After all, it is a large investment, and an opportunity to save potential lost revenues.

\section{CONCLUSION}

Since every company is different, it will require various levels of analyses to identify the factors that impact absenteeism for a specific employer. If absenteeism is identified as a significant problem, the company will need to take a hard look at the cause of the problem and begin to consider strategies to recapture lost revenues. Furthermore, as the economy tightens and the related financial stress increases for most employees, it is very likely that employers may see an increase in absenteeism due to stress related issues. The more aware a company is of issues related to employee absenteeism, the more successful they will be in implementing strategies to reduce the related cost and increase productivity. One study cited evidence that options to work from home, reduced workweeks and standard weekday work hours were helpful in reducing absenteeism. Shift work and compressed work schedules, however, led to increased absenteeism. Other studies show that allowing workers to have more input into decisions that affect their jobs and increasing their responsibilities, when appropriate, makes jobs more interesting with improved productivity. Thus, job satisfaction was shown to be an important factor in decreased absences. Workers who were satisfied or very satisfied with their jobs were .83 times less likely to be absent than individuals who were less satisfied with their jobs (Dionne \& Dostie, 2007).

Robert Levering and Milton Moskowitz oversee Fortune magazine's annual list of the 100 Best Companies to Work For project. Their research indicates that industry by industry these 100 Best Companies have $50 \%$ less turnover than other companies. "Publicly traded companies on this list average 15 to 25 percent greater return for investors than the S\&P 500 over three, five and ten-year periods" (Levering and Moskowitz). Implementing programs to decrease absenteeism will not only improve employee morale but is also good for the bottom line. 
Table 1: Statistics Canada: Absence Rates for Full-Time Employees - Canada

\begin{tabular}{|l|c|c|c|c|c|c|c|c|c|c|}
\hline & \multicolumn{9}{|c|}{ Incidence } & \multicolumn{3}{c|}{ Inactivity rate } & \multicolumn{3}{c|}{ Days lost per worker in year } \\
\hline & Total & $\begin{array}{c}\text { Illness or } \\
\text { disability }\end{array}$ & $\begin{array}{c}\text { Personal or } \\
\text { family } \\
\text { responsibilities }\end{array}$ & Total & $\begin{array}{l}\text { Illness or } \\
\text { disability }\end{array}$ & $\begin{array}{c}\text { Personal or } \\
\text { family } \\
\text { responsibilities }\end{array}$ & Total & $\begin{array}{c}\text { Illness or } \\
\text { disability }\end{array}$ & $\begin{array}{c}\text { Personal or family } \\
\text { responsibilities }\end{array}$ \\
\hline \multicolumn{9}{|c|}{ Percent } \\
\hline
\end{tabular}

Source: Statistics Canada 2008

\section{AUTHOR INFORMATION}

Mehmet C. Kocakülâh, Ph.D. is professor of accounting at the University of Southern Indiana, Evansville, Indiana.

Ann Galligan Kelley, CPA is an Associate Professor of Accountancy at Providence College and Director of the Business Studies Program.

Krystal M. Mitchell, Capital Management Coordinator, LifePoint Hospitals, Inc. Nashville, TN.

Margaret P. Ruggieri, CPA is an Assistant Professor of Accountancy at Providence College.

\section{REFERENCES}

1. Brown, David. (2003, November). "CIBC day care saves 2,500 absence days". Canadian HR Reporter. 16: 1 .

2. Dionne, Georges \& Dostie, Benoit. (2007, October). "New evidence on the determinants of absenteeism using linked employer-employee data," Industrial and Labor Relations Review, Cornell University, 61(1), 108-120.

3. Easton, Fred F., Goodale, John C. (2005) "Schedule recovery: Unplanned absences in service operations", Decision Sciences 36 (3), 459-488

4. -----, "The economics of wellness: Stress, illness, and absenteeism can take a huge toll". Canadian Business. 76 (December 2003).

5. Felix, Sonya. (1998, June). "Putting agenda on the right track". Benefits Canada, Toronto, 22(6), 44-48.

6. Haswell, Matt. "Dealing with employee absenteeism”. Management Services. 47 (December 2003 ): 16.

7. Jackson, Jennifer L. (2008, June). "Win-Win-Win: Employers, employees, and the environment" Global Politician.

8. Kaleta, Sharon, Edward, Anderson. (2003, November). "Here today, gone tomorrow: Employee absence and the evaporating workforce". National Underwriter. 1.

9. Lombardo, Tony. (2003, May). "Some experts say cost of workplace absenteeism on rise". Knight Ridder Tribune Business News. 1.

10. Neuborne, Ellen. (2003, January). “The carrot, not the stick”._Potentials__36, 39-41.

11. O'Reilly, S. (2008, June 3). Personnel Today. 
12. Poirier, Wendy. (2003, November). “Managing absence versus eliminating its causes”. Canadian HR Reporter. 16, 15.

13. Quinley, Kevin. (2003, February). "EAPs: A benefit that can trim your disability and absenteeism costs". Compensation \& Benefits Report. 17, 6-8.

14. ----, "Strategies that can help you deal with excessive absences". HR Focus. 80 (December 2003): 9.

15. Truman, Dave. (2003, November). "Ohio companies try to encourage employees not to take sick days". Knight Ridder Tribune Business News. 1.

16. United States Bureau of Labor Statistics (2007): ftp://ftp.bls.gov/pub/special.requests/lf/aat46.txt

17. Whittle, Sally. (2004, February). "Know where your workers are". Human Resources. 46-50.

18. "Worldwide stress". Employment Bulletin and IR Digest (1993). Bradford, 9(1), 6-7.

\section{NOTES}

